Research Article

\title{
Comparative Productive Performance among three Plumage Varieties of Noiller Hens
}

\section{Paul Oludare Adetunji* and Safiriyu Idowu Ola}

Department of Animal Sciences, Obafemi Awolowo University, 220005, Ile-Ife, Osun State, Nigeria.

Abstract | Noiler is an improved indigenous dual-purpose breed of chicken developed in Nigeria to meet national demands for food supply. The objective of this study is to compare the productive performance among three prominent plumage varieties of Noiler hens. For this purpose, a total of 90 pullets with three plumage colours (brown, black and barred) were divided into 3 replicates with 10 birds per replicate in each of the variety. Data were collected on the pubertal parameters (age at first egg and crouching behaviour) from 16-22 weeks of age; egg production performance indices (egg weight, hen day egg production-HDEP, feed efficiency-FE/ dozen eggs and persistency of lay) from 19-52 weeks of age. Additionally, sexual ornaments' morphometry (Comb Length-CL, Comb Height-CH, Wattle Length-WL, Wattle Height-WH and Inter Pubic DistanceIPD) was determined from 16-24 weeks of age. Data on puberty and egg production performance indices were subjected to Analysis of Covariance with body weight at puberty as a covariate, while morphometry measurements were subjected to Spearman correlation analysis. Plumage colour difference had a significant $(\mathrm{P}<0.05)$ effect on the onset of puberty as lower age at first egg were recorded in brown and black pullets compared to the barred pullets. Black hens had the best performance in most of the egg production indices with the values of $61.57 \pm 0.56 \mathrm{~g}, 68.38 \pm 2.49 \%, 157 \pm 3.55 \mathrm{eggs}, 2.39 \pm 0.05, \mathrm{NGN} 266.56 \pm 8.31$ and 12 weeks (at $85.37 \%$ ) for egg weight at $52^{\text {nd }}$ week of age, HDEP, number of eggs per period (224 days), FE/dozen eggs, cost/dozen eggs and persistency of lay, respectively. The CL and WL positively and significantly $(\mathrm{P}<0.05)$ correlated ( $\mathrm{r}=0.22$ to 0.57$)$ with egg production performance indices, except egg weight but negatively related ( $r=-0.11$ to -0.36$)$ to age at first egg in all three varieties, while IPD was positively correlated with egg weight in brown $(r=0.43)$ and black $(r=0.53)$ hens. Collectively, these results demonstrate that black and brown hens could be preferred over barred hens for egg production. Sexual ornament morphometry such as CL, WL and IPD may be used to predict onset of puberty and some egg production performance traits in the tested plumage varieties of Noiler hens.

Received | June 08, 2020; Accepted | August 23, 2020; Published | October 16, 2020

*Correspondence | Paul Oludare Adetunji, Department of Animal Sciences, Obafemi Awolowo University, 220005, Ile-Ife, Osun State, Nigeria; Email: adetunjioludare@gmail.com

Citation | Adetunji, P.O. and S.I. Ola. 2020. Comparative productive performance among three plumage varieties of noiler hens. Sarhad Journal of Agriculture, 36(4): 1079-1087.

DOI | http://dx.doi.org/10.17582/journal.sja/2020/36.4.1079.1087

Keywords | Egg production, Laying persistency, Noiler chicken, Sexual ornaments, Correlation

\section{Introduction}

$\mathrm{O}$ nset of puberty (lay) is of great economic importance in the layer stock. Farmers would want to know if a strain is early or late maturing and since there are many strains competing for patronage, both scientific and layman means of identifying hen's maturity would be beneficial to the farmers. Egg production and its related traits such as age and body weight at first egg, rate of laying and egg size are economic traits which were reported to have wide variations among breeds and/or strains 
of chickens (Iraqi et al., 2002). Persistency of egg laying which is the period during which the peak production is maintained, is a trait of both economic and environmental importance (Bain et al., 2016).

It has been reported that onset of puberty significantly correlates with comb mass and the female comb size correlates with number of eggs produced and total egg output (Wright et al., 2008, 2012). Rydmel (2010) has also noted that, comb size and weight have a correlated response with egg number and mean egg weight in different strains or varieties of chickens.

Noiler is an improved indigenous chicken breed in Nigeria developed by Amo Farm Limited, with the primary aim of improving the food and financial security of small poultry holders of the rural populace especially women. Few publications available on Noiler chicken have proved the potentials in this chicken for meat and egg production (Bamidele et al., 2019; Suleiman et al., 2019). Therefore, the objectives of this study were to compare onset of puberty, egg production performance and correlations between sexual ornaments and productive performance traits among the prominent plumage colour varieties of Noiler hens. This will help both the farmers and breeders in selecting the best performing variety for rearing and possibly further genetic improvement.

\section{Materials and Methods}

The study was carried out between February and November, 2019 on Noiler chicken maintained at a commercial poultry farm located at Koola Village, Modakeke within Ile-Ife region, Nigeria. Laboratory analyses were carried out at Animal Reproduction Laboratory, Department of Animal Sciences, Obafemi Awolowo University, Ile-Ife, Nigeria.

\section{Experimental animals}

A total of 90 Noiler pullets of 14 week of age were included in the study. These birds were of three plumage colours (brown, black and barred). They were acclimatised for two weeks, and so actual data collection started at $16^{\text {th }}$ week of age.

\section{Management practices}

The chickens were housed individually in battery cages with nipple drinkers and convenient feeding troughs. They were fed on commercial grower mash (minimum $15 \% \mathrm{CP}$ and $2600 \mathrm{Kcal} / \mathrm{kg}$ ) from $14^{\text {th }}$ to $18^{\text {th }}$ week of age. Thereafter, they were maintained on commercial layer mash (minimum $16.5 \% \mathrm{CP}, 2650 \mathrm{Kcal} / \mathrm{kg} \mathrm{ME}$ ) from the $19^{\text {th }}$ week to the end of the experiment $\left(52^{\text {nd }}\right.$ week of age). Fresh and clean water was given $a d-$ libitum. Routine and occasional poultry management practices were observed. Newcastle disease vaccine (Lasota) and other medications were administered when necessary. The surroundings of the pen were kept clean and litters was packed on time to prevent the build-up of ammonia.

\section{Data collection}

Experimental design: The 90 pullets comprise 30 each of the three plumage types and divided into 3 replicates with 10 birds per replicate in a completely randomized design, using weight at puberty as a covariate.

Onset of puberty: Pullets were monitored individually on a daily basis from $16^{\text {th }}$ week of age until the first egg was sighted and recorded.

Egg laying performance: Data collected on egg laying parameters include daily egg number and average egg weight on a weekly basis. Hen Day Egg Production (HDEP), Hen House Egg Production (HHEP), feed conversion per dozen eggs and persistency of lay were obtained through calculations.

Hen Day Egg Production (HDEP) $=\frac{\text { Number of eggs produced per day }}{\text { Number of hens alive per day }} \times 100$
Hen House Egg Production (HHEP) $=\frac{\text { Number of eggs laid during the period }}{\text { Hen housed at the beginning of the period }} \times 100$
Feed Efficiency per dozen eggs (FE/dozen eggs) $=\frac{\text { Kilogram of feed consumed }}{\text { Total number of eggs laid }} \times 12$

Egg weight: Individual egg was weighed with a sensitive top loading scale within 24 hours of being laid. This was done twice every week.

Linear measurements of combs and wattles were taken from the $16^{\text {th }}$ week of age till $24^{\text {th }}$ week of age. Crouching behaviour was also monitored for the same period. All measurements except crouching were done using measuring tape following the procedure of FAO (2012).

Comb length (CL): It was measured as the maximum vertical distance from the front and the rear fingers of the comb.

Comb height $(\mathrm{CH})$ : This was taken as the maximum vertical distance from the highest peak to the base of the comb. 
Wattle length (WL): The measurement was done as the maximum horizontal distance between the front and the rear of the wattle.

Wattle height (WH): This was measured as the maximum vertical distance from the base to the distal end of the wattle.

Inter-pubic distance (IPD): It was measured as the distance between the two small bones guarding the vent opening.

Crouching bebaviour: This is the back bending or squatting response of a female chicken to touch attempt. Since each bird was housed in individual cage, this behaviour was monitored by opening the cage of each bird, an attempt was made to touch the back of the bird. The bird that bent back or squatted was scored as crouched and the one that did not was scored as not crouched. The percentage of crouched birds was thereafter calculated.

\section{Statistical analysis}

Data obtained for onset of puberty and egg production performance were subjected to Analysis of Covariance (ANCOVA) with weight at puberty as covariate using General Linear Model Procedure (PROC GLM) of SAS (2002). The linear measurement data were subjected to Spearman correlation using Procedure Correlation (PROC CORR) of the same version of SAS. Significant difference among the means values was separated at $5 \%$ significance level by Duncan Multiple Range Test (DMRT).

\section{Results and Discussion}

The influence of plumage colour varieties on the onset of puberty, body weight and crouching behaviour revealed that, there were significant differences in the age and weight at first egg, age at peak egg production and percentage crouching behavior among the plumage groups (Table 1). The average age at first egg in the brown hens was 133.28 days, black hens at 140.30 days and barred hens at 154.13 days. The highest body weight at the beginning of experiment $(2,091.15 \mathrm{~g})$ and at puberty $(2,935.25 \mathrm{~g})$ were recorded in the barred hens. Age at $50 \%$ production in brown hens (162.41 days) and black hens (166.32 days) were not significantly different, but lower $(\mathrm{p}<0.05)$ than 175.25 days recorded in the barred hens. Surprisingly, the barred hens reached peak egg production earlier than both brown and black hens at 191.38 days. Age at peak production for brown (210.62 days) and black (204.86 days) were not different $(p>0.05)$ from each other also.

Figure 1 shows the descriptive analysis of the crouching behavior among the plumage types. None of the birds crouched at $16^{\text {th }}$ week of age. There was a closed range of crouching percentage among the plumage varieties at $18^{\text {th }}$ week $(9.38 \%, 8.13 \%$ and $6.88 \%)$ and $20^{\text {th }}$ week of age $(33.75 \%, 31.88 \%$ and $31.25 \%)$ for brown, black and barred hens, respectively. However, distinct overall crouching percentages (85\%, 80\% and 75\%) were recorded at $22^{\text {nd }}$ week of age for brown, black and barred hens, respectively.

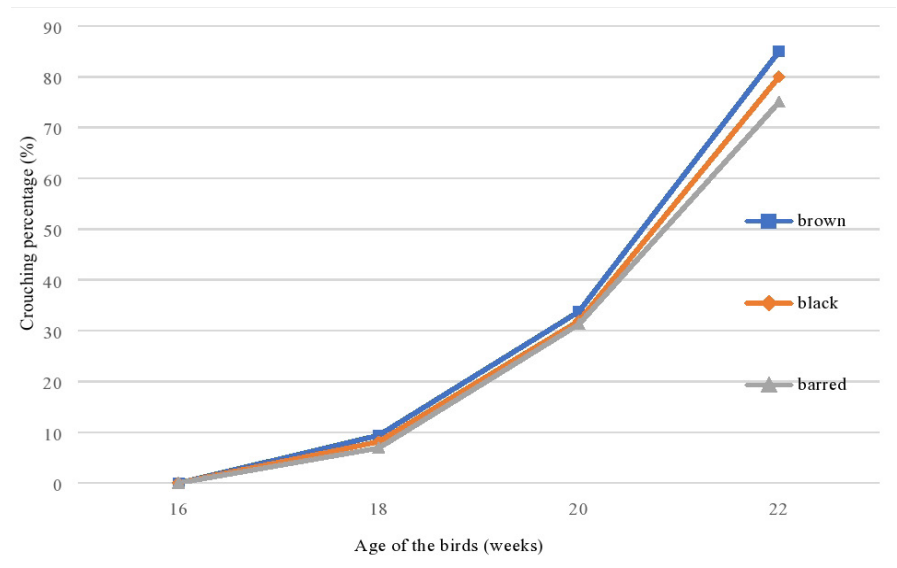

Figure 1: Crouching percentage among three plumage varieties of Noiler hens (16-22 weeks of age).

The effect of plumage colour varieties on egg production indices in the Noiler hens is presented in Table 2. Black hens produced more eggs per week (5.35), followed by the brown (4.21) and the lowest was recorded in the barred hens (3.28). There was no significant difference in the weight of first egg of the brown $(45.00 \mathrm{~g})$ and the black $(45.30 \mathrm{~g})$ hens, both of which were higher than that of the barred hens $(40.20 \mathrm{~g})$. Likewise, the average egg weight of the brown and black were also similar, but significantly $(\mathrm{P}<0.05)$ higher than that of the barred hens. The same pattern was also observed for the egg weight at $52^{\text {nd }}$ week of age with the values of $60.23 \mathrm{~g}, 61.57 \mathrm{~g}$ and $58.35 \mathrm{~g}$ for brown, black and barred hens, respectively. No mortality was recorded for the black hens out of the 30 hens used for the experiment whereas one and three mortalities were recorded for the brown and barred hens, respectively. Hen Day Egg Production (HDEP) varied significantly $(\mathrm{P}<0.05)$ among the varieties of hens with the highest value recorded for the black hens $(68.38 \%)$, followed by the brown hens $(57.24 \%)$ 
Table 1: Effect of plumage variety on the onset of puberty, body weight and crouching behaviour in Noiler pullets.

\section{Parameters}

Weight at $16^{\text {th }}$ week of age (g)

Weight at first egg $(\mathrm{g})$

Age at first egg (days)

Age at 50\% production (days)

Age at peak production (days)

Crouching percentage
Plumage colour

$\begin{array}{lllll}\text { Brown } & \text { Black } & \text { Barred } & \text { SEM } & \\ 1,858.40^{\mathrm{b}} & 1,849.55^{\mathrm{b}} & 2,091.15^{\mathrm{a}} & 26.77 & <0.0001 \\ 2,368.05^{\mathrm{b}} & 2,366.68^{\mathrm{b}} & 2,935.25^{\mathrm{a}} & 39.49 & <0.0001 \\ 133.28^{\mathrm{b}} & 140.30^{\mathrm{ab}} & 154.13^{\mathrm{a}} & 2.28 & 0.0068 \\ 162.41^{\mathrm{b}} & 166.32^{\mathrm{b}} & 175.25^{\mathrm{a}} & 3.25 & 0.0017 \\ 210.62^{\mathrm{a}} & 204.86^{\mathrm{a}} & 191.38^{\mathrm{b}} & 3.89 & 0.0003 \\ 85.00^{\mathrm{a}} & 80.00^{\mathrm{b}} & 75.00^{\mathrm{c}} & 1.13 & <0.0001\end{array}$

abc within rows, means with different superscripts differ at $p<0.005$; SEM: standard error of the mean.

Table 2: Effect of plumage varieties on the egg production parameters of Noiler hens.

\begin{tabular}{|c|c|c|c|c|c|}
\hline \multirow[t]{2}{*}{ Parameters } & \multicolumn{3}{|c|}{ Plumage varieties } & \multirow{2}{*}{$\begin{array}{l}\text { Group } \\
\text { SEM }\end{array}$} & \multirow[t]{2}{*}{ p value } \\
\hline & Brown & Black & Barred & & \\
\hline Number of eggs/hen/week (count) & $4.21^{b}$ & $5.35^{\mathrm{a}}$ & $3.28^{c}$ & 0.13 & $<0.0001$ \\
\hline Weight of first egg $(\mathrm{g})$ & $45.00^{\mathrm{a}}$ & $45.30^{\mathrm{a}}$ & $40.20^{b}$ & 0.79 & 0.0005 \\
\hline Overall average egg weight (g) & $58.54^{\mathrm{a}}$ & $59.32^{\mathrm{a}}$ & $55.39^{\mathrm{b}}$ & 0.88 & 0.0005 \\
\hline Egg weight at 52 weeks of age (g) & $60.23^{\mathrm{a}}$ & $61.57^{\mathrm{a}}$ & $58.35^{\mathrm{b}}$ & 0.56 & 0.0037 \\
\hline Cumulative mortality (count) & 1.00 & 0.00 & 3.00 & & \\
\hline Average HDEP: $19-52$ weeks of age (\%) & $57.24^{\mathrm{b}}$ & $68.38^{a}$ & $50.06^{c}$ & 2.49 & $<0.0001$ \\
\hline Average HHEP: 19-52 weeks of age (\%) & $56.14^{\mathrm{b}}$ & $68.38^{a}$ & $48.22^{c}$ & 2.56 & $<0.0001$ \\
\hline Egg number/bird (count) (days) & $138.43^{\mathrm{b}}(231)$ & $157.45^{\mathrm{a}}(224)$ & $102.11^{\mathrm{c}}(217)$ & 3.55 & $<0.0001$ \\
\hline Percentage egg number per bird (\%)(days) & $59.93^{\mathrm{b}}(231)$ & $70.29^{a}(224)$ & $47.06^{c}(217)$ & 0.41 & $<0.0001$ \\
\hline Feed offered/bird/day (g) & 115 & 115 & 115 & 0.00 & 1.0000 \\
\hline Feed efficiency/dozen egg & $2.65^{\mathrm{b}}$ & $2.39^{c}$ & $3.11^{\mathrm{a}}$ & 0.05 & $<0.0001$ \\
\hline Cost/dozen eggs (NGN)* & $312.80^{\mathrm{b}}$ & $266.56^{c}$ & $398.48^{a}$ & 8.31 & 0.0004 \\
\hline
\end{tabular}

abc within rows, means with different superscript differ at p<0.05; SEM: standard error of the mean; HDEP: Hen Day Egg Production; HHEP: Hen House Egg Production; NGN: Nigerian Naira. *: a crate of commercial layers' egg (30 eggs) is being sold for the range of NGN800-NGN950 in Nigeria depending on time (season) and size.

Table 3: Means of sexual ornaments morphometry traits in Noiler hens (16-22 weeks of age).

\begin{tabular}{llllll} 
Parameters & \multicolumn{2}{c}{ Plumage varieties } & Group & p value \\
Comb length $(\mathrm{cm})$ & Brown & Black & Barred & SEM & \\
Comb height $(\mathrm{cm})$ & $4.83^{\mathrm{a}}$ & $4.09^{\mathrm{c}}$ & $4.54^{\mathrm{b}}$ & 0.07 & $<0.0001$ \\
Wattle length $(\mathrm{cm})$ & $2.31^{\mathrm{a}}$ & $2.03^{\mathrm{b}}$ & $1.87^{\mathrm{c}}$ & 0.05 & $<0.0001$ \\
Wattle height $(\mathrm{cm})$ & $2.56^{\mathrm{b}}$ & $2.62^{\mathrm{b}}$ & $2.71^{\mathrm{a}}$ & 0.03 & 0.0019 \\
Inter pubic distance $(\mathrm{cm})$ & 2.18 & 2.16 & 2.25 & 0.04 & 0.2597 \\
& $3.52^{\mathrm{b}}$ & $3.38^{\mathrm{b}}$ & $4.18^{\mathrm{a}}$ & 0.06 & $<0.0001$
\end{tabular}

abc within rows, means with different superscript differ at $p<0.05$; SEM: standard error of the mean.

and the barred hens (50.06\%). The same order of significance was also recorded for the Hen House Egg Production (HHEP). Since there was no mortality recorded in the black hens, then HHEP equals HDEP. The black hens on the average produced a total number of 157.45 eggs for the period of 224 days (70.29\%). This was significantly higher than 138.43 eggs produced by the brown hen for 231 days
(59.93\%) and 102.11 eggs produced by the barred hen for the period of 217 days (47.06\%). The same amount $(115 \mathrm{~g})$ of feed was offered to each bird per day across the varieties. The lowest significant $(\mathrm{P}<0.05)$ value of feed efficiency per dozen egg (2.39) was recorded in the black hens, highest in the barred hens (3.11). Highest significant cost/dozen eggs was recorded in the barred hens (NGN398.48), followed 


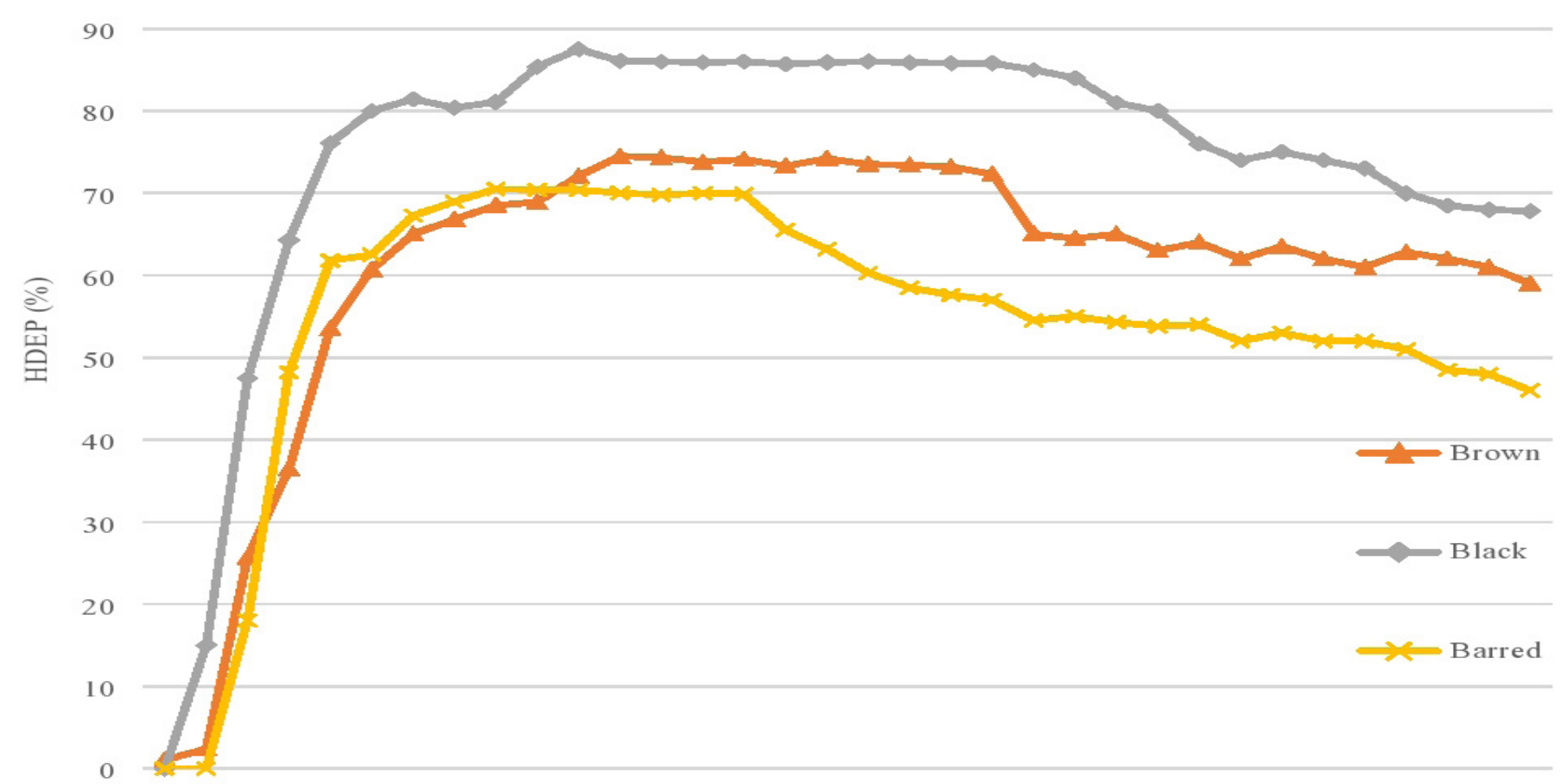

19202122232425262728293031323334353637383940414243444546474849505152 Age of the bird (weeks)

Figure 2: Hen day egg production (HDEP) persistency among three varieties of Noiler hens.

by the brown hens (NGN312.80) and the lowest was recorded in the black hens (NGN266.56).

The result presented in Figure 2 describes the HDEP persistency of laying in the three plumage varieties of Noiler hens. The highest HDEP of $85.37 \%$ was recorded in the black hens in the $29^{\text {th }}$ week of age and it persisted till $41^{\text {st }}$ week of age making up 12 weeks of persistent peak production. The highest HDEP in the brown variety was $74.5 \%$, persistency of peak laying lasted for 9 weeks $\left(30^{\text {th }}-39^{\text {th }}\right.$ weeks of age $)$. The lowest HDEP was found in the barred variety hens with the highest peak value of $70.75 \%$ and the persistency of laying only lasted for 6 weeks $\left(27^{\text {th }}-33^{\text {rd }}\right.$ weeks of age $)$ before a drastic reduction in egg laying.

Variations in the sexual ornaments' morphometry among the three varieties of Noiler hens is presented in Table 3. Comb length and height were significantly different $(\mathrm{P}<0.05)$ among the varieties of hens with the highest value recorded in the brown hens. There was no significant difference between the wattle length of the brown and black hens but lower than that of the barred hens. Wattle height was not significantly $(P>0.05)$ different among the three varieties of hens. Inter pubic distance of $4.18 \mathrm{~cm}$ recorded for the barred variety was significantly higher than that of brown
$(3.52 \mathrm{~cm})$ and black $(3.38 \mathrm{~cm})$ varieties which were not different from each other.

Coefficients of phenotypic correlations among sexual ornaments, onset of puberty and egg production indices are shown in Table 4. In the brown and black pullets, CL and WL positively correlated with egg number, HDEP and HHEP with coefficient of correlation ranging from 0.16 to 0.57 . Likewise, positive correlation was noticed between inter-pubic distance and egg weight in the brown and black hens. The CL and WL of the barred hens positively correlated ( $r=0.11$ to 0.48$)$ with egg number, HDEP and HHEP. There was a strong correlation between Inter Pubic Distance (IPD) and egg weight in brown ( $r=0.43)$ and black $(r=0.53)$ hens. A high and positive correlation ( 0.73 ) was observed between IPD and weight at puberty in the barred hens. Mostly, measures of sexual ornaments, IPD and crouching behaviour were negatively related to age at first egg $(\mathrm{r}=-0.11$ to -0.87$)$.

The range of 133.28 - 154.13 days for age at first egg recorded in this study across all the three plumage varieties of Noiler pullets is higher than $130 \pm 1.8$ days reported for the same Noiler chicken by Bamidele et al. (2019). The disparity could be linked to 
Table 4: Phenotypic correlation coefficients among sexual ornaments, onset of puberty and egg production parameters among three plumage varieties of Noiler hens.

\begin{tabular}{|c|c|c|c|c|c|c|c|}
\hline \multirow{2}{*}{$\begin{array}{l}\text { Sexual ornaments' } \\
\text { morphometry }\end{array}$} & \multicolumn{6}{|c|}{ Egg production parameters and onset of puberty } & \multirow{2}{*}{$\begin{array}{l}\text { Plumage } \\
\text { variety }\end{array}$} \\
\hline & Egg number & Egg weight & HDEP & HHEP & Age at first egg & Weight at puberty & \\
\hline $\begin{array}{l}\text { Comb } \\
\text { Length }\end{array}$ & $\begin{array}{l}0.46^{* *} \\
0.57^{* * *} \\
0.32^{* * *}\end{array}$ & $\begin{array}{l}-0.53^{* *} \\
0.15^{+} \\
0.09^{+}\end{array}$ & $\begin{array}{l}0.37^{* *} \\
0.46^{* *} \\
0.18^{*}\end{array}$ & $\begin{array}{l}0.25^{*} \\
0.39^{* *} \\
0.27^{*}\end{array}$ & $\begin{array}{l}-0.24^{*} \\
-0.23^{*} \\
-0.11^{+}\end{array}$ & $\begin{array}{l}-0.22^{*} \\
-0.24^{*} \\
-0.26^{*}\end{array}$ & $\begin{array}{l}\text { Brown } \\
\text { Black } \\
\text { Barred }\end{array}$ \\
\hline $\begin{array}{l}\text { Comb } \\
\text { Height }\end{array}$ & $\begin{array}{l}-0.43^{* *} \\
0.29^{*} \\
-0.34^{* *}\end{array}$ & $\begin{array}{l}-0.06^{+} \\
-0.24^{*} \\
-0.14^{+}\end{array}$ & $\begin{array}{l}-0.26^{*} \\
0.16^{*} \\
0.13^{\dagger}\end{array}$ & $\begin{array}{l}-0.33^{* *} \\
0.12^{\dagger} \\
-0.33^{*}\end{array}$ & $\begin{array}{l}-0.19^{*} \\
0.14^{*} \\
-0.10^{+}\end{array}$ & $\begin{array}{l}-0.01^{\dagger} \\
-0.14^{+} \\
-0.17^{*}\end{array}$ & $\begin{array}{l}\text { Brown } \\
\text { Black } \\
\text { Barred }\end{array}$ \\
\hline $\begin{array}{l}\text { Wattle } \\
\text { Length }\end{array}$ & $\begin{array}{l}0.32^{*} \\
0.54^{* *} \\
0.51^{* *}\end{array}$ & $\begin{array}{l}0.22^{*} \\
0.01^{\dagger} \\
0.05^{\dagger}\end{array}$ & $\begin{array}{l}0.34^{* * *} \\
0.44^{* *} \\
0.32^{* *}\end{array}$ & $\begin{array}{l}0.27^{*} \\
0.31^{*} \\
0.44^{* *}\end{array}$ & $\begin{array}{l}-0.36^{* *} \\
-0.25^{\dagger} \\
-0.25^{*}\end{array}$ & $\begin{array}{l}0.10^{+} \\
0.31^{*} \\
0.31^{*}\end{array}$ & $\begin{array}{l}\text { Brown } \\
\text { Black } \\
\text { Barred }\end{array}$ \\
\hline $\begin{array}{l}\text { Wattle } \\
\text { Height }\end{array}$ & $\begin{array}{l}0.15^{\dagger} \\
0.19^{\dagger} \\
-0.19^{\dagger}\end{array}$ & $\begin{array}{l}-0.13^{\dagger} \\
-0.24^{*} \\
-0.33^{*}\end{array}$ & $\begin{array}{l}-0.14^{\dagger} \\
-0.08^{\dagger} \\
-0.17^{\dagger}\end{array}$ & $\begin{array}{l}-0.18^{*} \\
0.11^{\dagger} \\
-0.28^{*}\end{array}$ & $\begin{array}{l}-0.13^{\dagger} \\
-0.28^{*} \\
0.21^{+}\end{array}$ & $\begin{array}{l}0.39^{* *} \\
-0.27^{*} \\
-0.10^{\dagger}\end{array}$ & $\begin{array}{l}\text { Brown } \\
\text { Black } \\
\text { Barred }\end{array}$ \\
\hline $\begin{array}{l}\text { Inter Pubic } \\
\text { Distance }\end{array}$ & $\begin{array}{l}-0.26^{*} \\
-0.06^{\dagger} \\
-0.45^{* *}\end{array}$ & $\begin{array}{l}0.43^{* *} \\
0.53^{* *} \\
-0.47^{* *}\end{array}$ & $\begin{array}{l}-0.06^{+} \\
-0.28^{*} \\
-0.33^{*}\end{array}$ & $\begin{array}{l}-0.33^{*} \\
-0.13^{+} \\
-0.03^{+}\end{array}$ & $\begin{array}{l}-0.39^{* * *} \\
-0.39^{* *} \\
0.25^{\dagger}\end{array}$ & $\begin{array}{l}0.20^{*} \\
0.36^{* *} \\
0.73^{* * *}\end{array}$ & $\begin{array}{l}\text { Brown } \\
\text { Black } \\
\text { Barred }\end{array}$ \\
\hline $\begin{array}{l}\text { Crouching } \\
\text { Behaviour }\end{array}$ & $\begin{array}{l}0.10^{\dagger} \\
-0.32^{*} \\
-0.31^{*}\end{array}$ & $\begin{array}{l}0.08^{\dagger} \\
-0.24^{*} \\
0.17^{\dagger}\end{array}$ & $\begin{array}{l}-0.25^{*} \\
-0.13^{\dagger} \\
-0.29^{*}\end{array}$ & $\begin{array}{l}-0.24^{*} \\
-0.23^{*} \\
-0.15^{\dagger}\end{array}$ & $\begin{array}{l}-0.87^{\text {**** }} \\
-0.65^{* * * *} \\
-0.24^{*}\end{array}$ & $\begin{array}{l}-0.38^{* *} \\
-0.04^{\dagger} \\
-0.05^{\dagger}\end{array}$ & $\begin{array}{l}\text { Brown } \\
\text { Black } \\
\text { Barred }\end{array}$ \\
\hline
\end{tabular}


HDEP: Hen Day Egg Production; HHEP: Hen House Egg Production; correlation coefficients, $r$ of 0.10 to 0.30 (low correlation), 0.31 to 0.50 (medium correlation), 0.51 to 1.00 (high correlation).

management system. Bamidele's experimental birds were kept on deep litter system and thus age at first egg couldn't have been for individual birds, unlike our birds that were housed individually in battery cages. Also, Bamidele's experiment on Noiler birds was carried out in more than one location, and thus the data reported must have been average of multiple locations. Our result is also higher than 110-127 days reported for Bovan Nera, Isa Brown and FUNAAB Alpha (FACD, 2018; Jesuyon and Isidahomen, 2015), which are other breeds adapted to tropical environment. This difference could be as a result of amount of feed intake or breeds effect, because Bovan Nera and Isa Brown are well known layer breeds.

It was expected that the barred hens would lay the first egg considering their higher body weight at the beginning of the experiment and at puberty. However, the reverse was the case, which agrees with the report of FACD, 2018 where higher age at first egg was recorded for the broiler line of FUNAAB Alpha chickens in comparison to the pullet line. Therefore, the result of the present study suggests that brown and black hens could be the pullet lines of Noiler chicken, while barred hens could probably represent the broiler line. The age at $50 \%$ and peak production recorded in this study are lower than 217 days (age at 50\% production) and 308 days (age at peak production) reported for FUNAAB Alpha chickens (FACD, 2018), which suggest Noiler chicken could be a better laying breed. The highest percentage of crouching behaviour recorded for the brown hens at puberty affirmed the result of age at first egg, because the brown hens laid first. Thus, crouching behaviour besides other confounding effects could be a good indicator of age at first lay.

The average egg weight of (55.54-59.32) $\pm 0.88 \mathrm{~g}$ recorded in this study is comparable to $56 \mathrm{~g}$ reported by Bamidele et al. (2019) for the same Noiler chickens intensively reared on deep litter. However, the result is higher than the mean egg weight of $54.3 \pm 0.21 \mathrm{~g}$ reported for Algerian indigenous naked-neck chickens by Dahloum et al. (2018) which showed that, blackfeathered layers produced the biggest eggs compared to those from white and brown-feathered layers of the naked-neck chickens. In the present study, the blackfeathered Noiler hen also produced the biggest egg both for overall average egg weight and egg weight at $52^{\text {nd }}$ week of age, though not statistically significant from that of the brown hens. 
With regards egg number per bird, if projection is made into 52 weeks of laying (365 days), it means that, brown hens would produce approximately 223 eggs per annum and black hens, 270 eggs per annum which would be higher than 190 eggs per annum reported for FUNAAB Alpha chicken (FACD, 2018). However, this projection might be subjected to the effect of mortality and decrease in egg number as birds advance in age. Nevertheless, these two Noiler varieties appear to have potential to compete with commercial layer lines that produce average egg number of 250-300 eggs per annum (Tadelle and Fasil, 2016). The maximum HDEP (70.5\%-85.37\%) recorded among the three varieties in this study are better than $61 \pm 0.6 \%$ reported by Bamidele et al. (2019) for the same Noiler hens intensively reared on deep litters. Also, the range of (2.39-3.11) recorded for FE/ dozen egg among the three varieties hens are lower (better) than $4.6 \pm 2.1,3.1 \pm 1.3$ and $3.6 \pm 0.9$ reported by Bamidele et al. (2019) for Fulani, FUNAAB Alpha and Noiler breeds, respectively. In the present study, a particular quantity of feed was given to the birds, they were reared in battery cages (which could have aided the conversion of feed to eggs) and FE/dozen eggs was calculated at the end of 31-33 weeks of laying, whereas in the study of Bamidele et al. (2019), birds were fed ad-libitum, reared intensively on deep litters and FE/dozen eggs was calculated at the end of 34-36 weeks of laying. Black hens proved to be the hardiest among the three varieties as no mortality was recorded throughout the experiment.

Improving existing or developing new breeds of layers with longer length of laying appears to be one of the most logical approach to the efficient utilisation of resources as the benefits are both financial and environmental (Bain et al., 2016). The persistency of lay of 12 weeks (29-41 weeks of age) at $85.37 \%$ reported in black hens in this study is higher than 10 weeks (29-39 weeks of age) at $80 \%$ reported for FUNAAB Alpha chicken (FACD, 2018).

The comb length obtained in this study for all the three varieties is higher but comparable to $3.58 \mathrm{~cm}$ reported by Shen et al. (2016) in a crossbred of White Leghorn and a Chinese indigenous strain of Dongxiang BlueShelled chickens. However, the comb height of $3.67 \mathrm{~cm}$ reported by the same authors is higher than $1.87 \mathrm{~cm}-$ $2.31 \mathrm{~cm}$ obtained in this study. This difference could be linked to the strains or breeds effect. Shen et al. (2016) reported that, large combs has a positive significant influence on the age at first egg. This opinion agreed with the result obtained for the brown Noiler hens in the present study, with their higher comb length and height as the first variety to lay egg. Inter pubic distance of $3.38-4.18 \mathrm{~cm}$ obtained in this study is higher than $2.5 \mathrm{~cm}$ or two adult fingers test reported in Wright et al. (2012) and MSUES (2019), for the $F_{2}$ intercross between a White Leghorn layer breed and a Red Jungle fowl population.

Negative correlation of age at first egg and comb length in brown and black hens is in line with Wright et al. (2012) who said that the gene responsible for increase in comb mass is also responsible for the decrease in onset of puberty. The strong and positive correlations ( $r=0.32$ to 0.52 ) observed in this study between comb length and total number of eggs laid for all the varieties disagreed with the report of Mukhtar and Khan (2012) who noted a negative correlation between these traits. However, it agreed with the report of Wright et al. (2012) and Rydmel (2010) who noted a positive correlation between comb size and number of eggs produced. Comb length ( $\mathrm{r}=$ 0.27 to 0.57$)$ and wattle length $(r=0.22$ to 0.54$)$ positively correlated with most of the egg production indices across all the three plumage varieties with increasing magnitude of coefficient of correlation from barred, brown to black varieties, respectively. This is similar to the reports of other researchers (Rydmel, 2010; Wright et al., 2012; Shen et al., 2016) with coefficients of correlation ranging from 0.10 to 0.62 and 0.14 to 0.59 for comb and wattle lengths, respectively. There was a strong negative relationship between the crouching behaviour and age at first egg with increasing magnitude of coefficient of correlation from barred, black and brown varieties. Other data in this study on crouching behaviour have earlier confirmed that this behavior could be a good indicator of onset of laying in the hens. In addition to crouching behaviour, inter pubic distance or two adult fingers test could also be employed as good indicator of onset of puberty in all the three plumage varieties of Noiler chickens. Expectedly, inter pubic distance had significant and positive correlations with egg weight in brown $(r=0.43)$ and black $(r=$ $0.53)$ varieties. However, an unexpected negative correlation $(r=-0.47)$ obtained for this same trait in the barred hens, could lead to a suggestion that the highest IPD of $4.18 \mathrm{~cm}$ recorded in this variety of hens could be due to their heavier body weight rather than potential egg weight. 
colour on egg quality characteristics of indigenous naked-neck chickens. Livest. Res. Rural

There was plumage varietal difference in onset of puberty in Noiler chickens. Black and brown hens had higher egg production indices and could be suitable for egg production purposes, whereas the barred hens appeared to be better for meat production. Comb and wattle lengths appear to be good predictors of egg number, hen day egg production and age at first egg in all the plumage varieties. Inter pubic distance could be a good predictor of egg weight in the black and brown hens.

\section{Novelty Statement}

The study has revealed different production performance of Noiler hens based on plumage colour varieties. This will be helpful to the farmers to select the most suitable variety to meet their preferred needs for egg or meat, as well as the breeding company to be aware of the market potentials for the different plumage varieties.

\section{Author's Contribution}

This publication is part of Mr. Paul Oludare Adetunji Master's degree thesis supervised by Professor Safiriyu Idowu Ola. POA conceived the idea, designed, carried out the study and prepared the manuscript for publication, while SIO supervised the study and proofread the manuscript for publication.

\section{Conflict of interest}

The authors have declared no conflict of interest.

\section{References}

Bamidele. O., E.B. Sonaiya, O.A. Adebambo and T. Dessie. 2019. On-station performance evaluation of improved tropically adapted chicken breeds for smallholder poultry production systems in Nigeria. Trop. Anim. Health Prod., 52: 1541-1548. https://doi.org/10.1007/s11250019-02158-9

Bain, M.M., Y. Nys and I.C. Dunn. 2016. Increasing persistency in lay and stabilising egg quality in longer laying cycles. What are the challenges? Br. Poult. Sci., 57(3): 330-338. https://doi. org/10.1080/00071668.2016.1161727

Dahloum, L., A. Yakubu and M. Halbouche. 2018. Effects of housing system and plumage
Dev., Volume 30, Article \#206. Retrieved October 6,2019, from http://www.Irrd.org/lrrd30/12/ abdul30206.html

FAO, 2012. Phenotypic characterization of animal genetic resources. FAO animal production and health guidelines No. 11. Rome. http://www. fao.org/docrep/015/i2686e/i2686e00.htm

Funaab Alpha Chicken Descriptor (FACD), 2018. Descriptor's format for poultry. Federal University of Agriculture, Abeokuta, Nigeria.

Iraqi, M.M., M.S. Hanafi, M.H. Khalil, A.F.M. El-Labban and M. Ell-Sisy. 2002. Genetic evaluation of growth traits in a crossbreeding experiment involving two local strains of chickens using multi-trait animal model. Livest. Res. Rural Dev., Volume 14, Article \#47. Retrieved September 26, 2019, from http://lrrd.org/ lrrd14/5/iraq145tmp.htm

Jesuyon, O.M.A. and C. Isidahomen. 2015. Canonical discriminant analysis of early maturity traits of parent stock layer strains in the tropics. Arch. Zoot., 18(1): 5-14.

Mukhtar, N. and S.H. Khan. 2012. Comb: An important reliable visual ornamental trait for selection in chickens. World's Poult. Sci. Assoc., 68: 425-434. https://doi.org/10.1017/ S0043933912000542

Mississipi State University Extension Service (MSUES). 2019. Culling hens. Identification of poor layers. Retrieved September 1, 2019, from extension.mssstate.edu/content/culling-hens.

Rydmel, S., 2010. Honesty of female sexual ornaments in Gallus gallus. MSc. thesis. Dep. Poult. Sci., Linkopin Univ., Sweden.

SAS, 2002. SAS user's guide. Statistical analysis system institute Inc., Cary, North Carolina.

Shen, M., L. Qu, M. Ma, T. Dou and J. Lu. 2016. Genome-wide association studies for comb traits in chickens. PLoS One, 11(7): e0159081. https://doi.org/10.1371/journal.pone.0159081

Suleiman, S., W. Hassan and O. Bamidele, O.2019. Growth performance of six tropically-adapted breeds in backyard flocks across Kebbi State, Nigeria. Proc. 44 ${ }^{\text {th }}$ Ann. Conf. Nigerian Soc. Anim. Prod., March 17th $-21^{\text {st }}, 2019$, UNIABUJA, ABUJA.

Tadelle, D. and G. Fasil. 2016. Shika brown breed: African chicken genetic gains more productive chickens for Africa's smallholders. Factsheet I. 
Retrieved on July 13, 2019, from https://core. ac.uk/download/pdf/132683017.pdf

Wright, D., S. Kerje, H. Brändström, K. Schütz, A. Kindmark, L. Andersson, P. Jensen and T. Pizzari. 2008. The genetic architecture of a female sexual ornament. Evolution, 62: 86-98. https:// doi.org/10.1111/j.1558-5646.2007.00281.x
Wright, D., D. Rubin, K. Schutz, S. Kerje, A. Kindmark, H. Brandstrom, L. Anderson, T. Pizzari and J. Per. 2012. Onset of sexual maturity in female chickens is genetically linked to loci associated with fecundity and a sexual ornament. Reprod. Domest. Anim., 47: 31-36. https://doi. org/10.1111/j.1439-0531.2011.01963.x 